\section{Casas de "tomar conta" e creches públicas: relações de cuidados e interdependência entre periferias e Estado}

\section{Camila Fernandes}

Universidade Federal do Rio de Janeiro | Rio de Janeiro, R], Brasil fernandesv.camila@gmail.com ORCID: http://orcid.org/0000-0003-2446-1760

RESUMO

Este artigo analisa as relações de coexistência entre as práticas informais de cuidados realizadas nas periferias e as administrações de Estado. A etnografia foi realizada num complexo de favelas situado na Zona Norte do Rio de Janeiro. A análise procura ressaltar as dinâmicas de interdependência entre as casas de moradoras de favela que "tomam conta" de crianças e as creches públicas. A partir das reflexões sobre os cuidados transacionados nesses espaços, busca-se refletir sobre as ideias de dependência, Estado provedor, sexualidade e reprodução feminina. A complementaridade entre esses lugares aponta para a existência de relações de cuidados nas quais dinâmicas de vulnerabilidade, escassez e demanda por recursos sociais são elementos de disputa que remetem a processos de reprodução estratificada de desigualdades históricas de gênero, classe, sexualidade, território e raça.

HOUSES FOR "TAKING CARE OF CHILDREN" AND PUBLIC DAYCARE CENTERS: RELATIONSHIPS OF CARE AND INTERDEPENDENCE BETWEEN PERIPHERIES AND THE STATE
DoI

http://DX.DOI.ORG/

$10.11606 / 1678-9857$

RA. 2020.189648

1 | Este artigo é fruto da tese de doutorado defendida no PPCAS do Museu Nacional (Fernandes, 2017), sob orientação de Adriana Viana, a quem agradeço a interlocução. Agradeço aos comentários de Claudia Fonseca, Luiz Fernando Dias Duarte e Maria Elvira Díaz-Benítez, bem como aos pareceristas anônimos. Agradeço aos membros do NUSEX, do PPCAS MN/UFR] e aos comentários realizados pelo Núcleo de Antropologia da Política (NUAP/PPCAS).

Um agradecimento

especial às donas das casas que permitiram a minha presença durante $o$ cotidiano e possibilitaram a realização deste trabalho.

\section{PALAVRAS-CHAVE}

Casas, creches, interdependência, cuidados, gênero

\section{KEYWORDS}

Homes, daycare centers, interdependence, care, gender 


\section{INTRODUÇÃO}

Neste artigo analiso a dinâmica de coexistência entre dois espaços voltados aos cuidados de crianças: as casas de "tomar conta" de crianças na favela e as creches públicas. O primeiro espaço diz respeito a uma atividade informal feita em casa por mulheres moradoras de favela e o segundo se refere a uma política pública formal realizada em instituições e gerida pelas administrações de Estado.

A etnografia foi realizada no complexo do São Carlos, uma área da Zona Norte do Rio de Janeiro que se situa entre os bairros do Catumbi, Estácio e Rio Comprido. O trabalho de campo se desenvolveu de forma multissituada entre março de $2014 \mathrm{e}$ janeiro de 2016 e incluiu observação cotidiana, conversas e algumas entrevistas focais. O material analisado se refere à pesquisa realizada em três casas de moradoras e três creches públicas. Nesses espaços, procurei entender as dinâmicas de cuidado exercidas entre ambos os lugares.

No início do trabalho de campo, pensava esses espaços em oposição e dotados de uma relativa autonomia. Tinha a impressão de que existia, de um lado, um lugar hiper-regulado e, do outro, um espaço aberto a negociações flexíveis. Durante o decorrer da pesquisa, essa imagem se manteve, entretanto, entendi que para além dessa distinção há uma relação de mutualidade entre as práticas exercidas que, por sua vez, é fundamental para a manutenção de uma estrutura desigual de acesso aos recursos sociais.

A partir da experiência dos sujeitos sociais nessas instâncias, procuro mostrar como a relação de complementaridade é essencial para pensar as fronteiras entre zonas de periferia, atuação do Estado, atividades formais, informalidade, domesticidade e institucionalidade. As antropólogas Veena Das e Deborah Poole (2004) lembram que um dos perigos de analisar a atuação estatal a partir da imagem de ordem consiste no fato de que essa ideia implica em pensar os espaços de periferias como lugares da desordem. Ao invés de identificar as favelas como áreas de falência do poder público, 0 que me interessa é acompanhar a forma como esses lugares são alvos de expedientes produzidos pelas ações estatais. Essa concepção permite compreender como a ideia de ausência de Estado estrutura as dinâmicas locais que revelam relações profundamente conectadas com os feitos das administrações públicas.

Nessa perspectiva, veremos que ambos os lugares possuem lógicas de funcionamento que são, de fato, muito distintas, porém, ao mesmo tempo, operam a partir de diferenças situacionais que são complementares. Isso é possível por meio da manutenção da informalidade e da vulnerabilidade nas casas de "tomar conta", junto à dinâmica contínua de produção da escassez promovida pela política de creches públicas. Ao final, veremos que a complementaridade entre esses espaços aponta para um circuito mais amplo de precariedade e desigualdade no qual os serviços de atenção a crianças são realizados majoritariamente por mulheres periféricas por meio 
de ajustes e gambiarras que apontam para a exploração, ocultamento e subalternidade de amplas cadeias desses locais de cuidados.'

O termo "tomar conta" trata-se de uma categoria nativa que diz respeito a um conjunto de gestos relativos ao universo dos cuidados e se refere tanto a dimensões positivas da ação: olhar, vigiar, dar carinho, alimentar, assim como as negativas, relativas a tarefas desagradáveis, coercitivas ou sujas; limpar, brigar, controlar e educar. Ao longo dos últimos anos, pesquisas sobre cuidados chamam atenção para a face polivalente de tais práticas (Hirata e Cuimarães, 2012; Debert, 2014; Molinier e Paperman, 2015; Sorj, 2016). Trata-se de atividades, serviços e trabalhos que perpassam diferentes domínios da experiência humana: amor, afeto, público, privado, trabalho produtivo, reprodutivo, ajuda, trabalho remunerado, dom e profissionalização (Debert e Pulhez, 2019; Zelizer, 2009). Dada a polissemia do termo "cuidado", ao longo desta análise escolhi manter a categoria êmica "tomar conta" uma vez que o sentido desse enunciado remete com precisão aos jogos de poder, controle e proteção aos quais os sujeitos estão envolvidos nas atividades de cuidados.

Nesse sentido, uma análise conjunta das casas e creches permite complexificar determinados modelos sociológicos que consideram a vida social feita a partir de domínios sociais isolados, tal qual na visão dos "mundos hostis", conceito cunhado pela socióloga Viviana Zelizer (2011). ${ }^{2}$ Esse dispositivo também permite pensar sobre a dimensão pragmática da gestão dos cuidados nas políticas públicas e no acesso aos direitos e recursos sociais.

No contexto das periferias, as práticas realizadas por mulheres que "tomam conta" fazem parte do que Vera da Silva Telles (2010) mapeou na configuração das cenas urbanas contemporâneas: a vida feita nas tênues fronteiras do informal e do formal. Trata-se de práticas que envolvem decisões, arranjos, subjetividades e expectativas que são geridas nas franjas das administrações de Estado. Em outra perspectiva, as práticas de "tomar conta" nas casas de moradoras de favelas são parte fundamental de uma estrutura social em que o cuidado das crianças nas classes populares é historicamente produzido em circulação, em modelos familiares de configuração estendida, a exemplo das práticas analisadas por Claudia Fonseca (1995a). Contudo, apesar da presença dessas práticas ser comum no âmbito das sociabilidades periféricas, é importante dizer que do ponto de vista normativo das leis sobre os direitos da criança e do adolescente, tais práticas são consideradas ilegais, uma vez que não correspondem aos critérios educativos e espaciais estabelecidos pelas definições formais de Estado.

As creches públicas são instituições financiadas pela Prefeitura do Rio de Janeiro por meio da Secretaria Municipal de Educação. A luta pelo acesso a uma creche é motivo de causas na justiça, a exemplo das ações movidas na Defensoria Pública do Estado do Rio de Janeiro e do fenômeno mais amplo de judicialização das vagas que obrigam os municípios a atenderem crianças além da capacidade das unidades (Finco, Gobbi e Faria, 2015). Anualmente, matérias realizadas na imprensa registram
1| Para um desenvolvimento dos sentidos da categoria "sujeito periférico" e "territórios periféricos", ver as análises de Tiaraju D`Andrea (2020) e Gabriel Feltran (2012).

2 |A pesquisa de Viviana Zelizer (2011) examina as interconexões entre práticas econômicas, relações de intimidade e atividades profissionais e fala sobre a visão dos "mundos hostis", ideia que diz respeito a domínios sociais distintos nos quais fronteiras devem ser preservadas afim de evitar a degradação de determinadas princípios, normas e valores morais relativos a cada campo de atuação. Esta concepção pensa a casa e a família como espaços puros de afeto e amor, situados em oposição ao "espaço público" feito de instituições, que por sua vez seria um lugar livre de sentimentos. 
os números alarmantes sobre famílias que não conseguem acesso às instituições. Somente no ano de 2019 "mais de 36 mil crianças estão na lista de espera por creche no Rio", conforme indicam os dados de jornais. ${ }^{3} \mathrm{O}$ acesso às creches é um problema estrutural da gestão pública e provoca efeitos de desigualdade durável com relação ao acesso ao mercado de trabalho e às oportunidades de profissionalização, com fortes impactos nas trajetórias de mulheres, pessoas negras e pobres. Por esse motivo, tratase de uma política pública interpelada por múltiplos marcadores sociais de gênero, classe, raça, sexualidade, território e idade.

As creches e as casas são espaços confrontados com a constante demanda pelo cuidado de crianças. Nesse contexto, esses são lugares nos quais discursos, falas e acusações sobre uma suposta reprodução feminina irresponsável ocupam um lugar central na explicação de determinadas "ausências" de responsabilidade do Estado. No decorrer da pesquisa, presenciei um conjunto de falas feitas pelos moradores sobre o fato de que as mulheres pobres "não se previnem" e "fazem filhos demais". De acordo com as narrativas locais, "as crianças são feitas umas atrás das outras" e "não são desejadas". Algumas falas associam esse fato à "violência", identificada como um fenômeno amplo encontrado na sociedade: "a criança nascida fora do tempo certo cresce sem estrutura e mais tarde vira um marginal", comenta um interlocutor. Outra linha discursiva presente nesse raciocínio, afirma que jovens "abandonados" se tornam pessoas "dependentes da ajuda do governo", conforme aludem falas ouvidas durante a pesquisa. Em suma, de acordo com a narrativa dos interlocutores, o excesso de pessoas na lista de espera para creches é explicado a partir da "irresponsabilidade" das mulheres pobres que, por não planejarem suas gestações, provocam a lotação dos espaços públicos e sua consequente ineficácia (Fernandes, 2017).

Esse conjunto de representações está presente também em atos e discursos de gestores públicos que aludem às mulheres que: "não se planejam para ter filhos". A título de exemplo, vale lembrar de uma determinada ocasião de trabalho de campo, quando um profissional do alto escalão da Secretaria de Educação da Prefeitura Municipal afirmou durante a inauguração de uma nova unidade de creche pública: "não adianta fazer mais creches, quanto mais creches tiver, mais filhos elas vão fazer", se referindo às moradoras de favela. Em outra ocasião, ao comentar sobre a lista de espera por vagas, outra gestora da Secretaria de Educação declarou que "independente de qualquer ação que o poder público possa tomar na política de creches, nada vai mudar enquanto não houver controle de natalidade", ao dissertar sobre o déficit de vagas.

Essas breves passagens possuem o objetivo de demonstrar que, embora em muitos casos os profissionais reconheçam que o acesso às políticas públicas dependa de investimentos políticos de diferentes ordens, esse reconhecimento nunca se desfaz sob a responsabilização das mulheres pobres na reprodução.

Apesar dos enquadramentos sobre alta fertilidade e uma sexualidade "irresponsável" supostamente exercida por mulheres pobres e moradoras de favela,
3 | Desse contingente, as Zonas Norte (29.946) e Oeste (43.669) da cidade são as mais afetadas em comparação as Zonas Sul (3.352) e Centro (3.549) com relação ao número de crianças que aguardam uma vaga (Morais, 2019) 
os dados estatísticos sobre a natalidade das mulheres brasileiras mostram que a cada censo demográfico as famílias possuem menos filhos. Essa queda de fecundidade se intensifica nas camadas mais pobres da população ${ }^{4}$. Ainda assim, durante o trabalho de campo, a presença de um discurso sobre a sexualidade e reprodução das mulheres pobres é extremamente presente e dotado de eficácia política. Tal representação se assemelha à imagem da "sexualidade tropical" desenvolvida pela antropóloga Adriana Piscitelli (2008a) ao analisar a trajetória de mulheres brasileiras que migram para países mais ricos. No contexto analisado por Piscitelli, a imagem das mulheres migrantes é associada à limpeza, domesticidade, propensão ao cuidado e sensualidade. Nas representações sobre mulheres de favela e periferias, a imagem da sensualidade se mantém, embora a sexualidade feminina seja frequentemente associada ao excesso. No tocante ao exercício da maternidade, tais mulheres são localizadas como "novinhas", "mães nervosas" ou "mães que abandonam os filhos" em exemplos de feminilidades desviantes que possuem forte apelo moral. Logo, as afirmações dessa ordem remetem a mulheres lascivas, hiper sexualizadas e irresponsáveis no campo da sexualidade e reprodução. As forças dessas dinâmicas de enquadramento incidem sobre os distintos modelos de guarda de crianças que operam em coexistência. Por esse motivo, esses são lugares fundamentais para entender a relação entre sexualidade, reprodução, gênero, raça, classe social e políticas públicas.

\section{MODELOS INFORMAIS DE CUIDADOS? A ATUAÇÃO DAS CASAS NA DEMANDA DE ATENÇÃO ÀS CRIANÇAS}

As casas de "tomar conta" são lugares em que mulheres moradoras da favela oferecem serviços de cuidados às crianças em suas próprias casas. Essa atividade é realizada na residência da mulher que "toma conta" de crianças, que também é a pessoa responsável pelo cuidado da sua casa e da sua família. As mulheres oferecem um conjunto de soluções de guarda para crianças. Os turnos de atendimento são flexíveis e funcionam na parte da manhã, tarde ou noite. Em algumas casas, as mulheres podem até dormir com as crianças, seja para trabalho noturno ou lazer das famílias. A idade das crianças é diversa, podem ser atendidas desde bebês até crianças de 10 anos de idade. O pagamento por essa atividade varia de acordo com cada casa, mas no geral, as mulheres cobram por volta de $\mathrm{R} \$ 200,00$ mensais para "tomar conta" das crianças.

Esse trabalho permite que muitas famílias trabalhadoras tenham mobilidade social, uma vez que os filhos se encontram aos cuidados desses serviços. Vale ressaltar que este é um modelo de atenção complementar ao cuidado oferecido pela creche, pela pré-escola e pela família (avós e parentes que ficam com as crianças), indicando que mesmo em um contexto no qual é possível recorrer aos familiares ou às instituições, o acionamento de outros meios de suporte é fundamental. Um exemplo dessa situação
4 | De acordo com último levantamento realizado pelo Ministério do Desenvolvimento Social, a partir de dados recolhidos da Pesquisa Nacional por Amostra de Domicílios (PNAD), feita pelo IBCE, "entre 2003 e 2013 enquanto o número de filhos até 14 anos caía 10,7\% no Brasil, as famílias $20 \%$ mais pobres do país - faixa da população que coincide com o público beneficiário do programa de complementação de renda - registravam uma queda mais intensa: $15,7 \%$. Para as mães das famílias $20 \%$ mais pobres do Nordeste, a queda foi ainda maior, alcançando $26,4 \%$ no período analisado" (Terra, 2015). Com base nesta pesquisa, outras reportagens noticiaram que "brasileiras estão tendo cada vez menos filhos": "o levantamento, do Ministério do Desenvolvimento Social e Combate à Fome, mostra ainda que a média de filhos por família caiu. Em 2003, era de 1,78. Em 2013, era de 1,59 filho por família" (Agência Brasil, 2015). 
se encontra no fato de que muitas crianças que permanecem durante um tempo nas creches, ainda precisam passar algumas horas aos cuidados das casas.

As mulheres que "tomam conta" de crianças possuem traços comuns em suas trajetórias de vida. Todas elas começaram essa atividade como uma forma de complementar a renda da família, que com o passar do tempo, tornou-se a principal fonte de sustento do grupo familiar. As mulheres são nascidas e criadas no morro e cuidam de crianças há mais de dez anos. Uma delas é "mãe solteira", como a própria se define. Duas delas são casadas e seus companheiros trabalham, um como zelador de uma igreja evangélica e outro como marceneiro autônomo. Nesses dois últimos casos, a renda obtida pelas mulheres é superior ao salário dos homens.

Nas três residências que acompanhei, outros parentes também participam das atividades de cuidados. Todas elas são filhas maiores e adolescentes que se encarregam de "ajudar" no cuidado das crianças, seja na alimentação, em brincadeiras, no apoio ao horário de dormir e nas demais atividades de entretenimento. Em uma das casas, há a presença de uma avó que também "ajuda" na rotina de cuidados. Essas "ajudas" feitas entre avós, mães e filhas são importantes de serem registradas uma vez que apontam para uma articulação entre gênero, casa e geração na gestão da vida cotidiana (Carsten e Hugh-Jones, 1995). ${ }^{5}$

Silvana é uma mulher de trinta e sete anos e se declara branca de cor. Ao relembrar de sua trajetória, conta que começou a cuidar de uma criança que era "malcuidada e os pais largavam". Com o tempo, outras crianças foram chegando em situações semelhantes e o que começou apenas como uma ajuda pontual tornou-se sua principal fonte de renda. Atualmente, faz dez anos que ela desenvolve esse trabalho. Em sua casa, ela conta com a "ajuda" de sua filha Bianca para dar conta dos cuidados de cerca de dez crianças. Silvana explica que não dorme com nenhuma criança em sua casa pois, em suas próprias palavras, "é importante ter um tempo só pra mim".

Em uma tarde em que estivemos juntas, Silvana contou sobre a história de Thiago, uma das primeiras crianças que ficou aos seus cuidados e, posteriormente, se tornou seu neto. Lívia, a mãe do menino, não tinha emprego fixo e vivia de bicos ${ }^{6}$, por conta dessa situação, passava por muitas dificuldades para criar a criança. Lívia e Bianca eram amigas e vizinhas, e, por esse motivo, a criança passou a ficar na casa de Silvana aos seus cuidados. Mãe e filha explicaram que a mãe biológica enfrentou muitas dificuldades e identificaram que ela não tinha "boas condições" para cuidar do seu filho. A criança frequentava a casa diariamente e, em um dado momento, começou também a dormir durante a noite, permanecendo mais tempo do que o combinado. De pouco a pouco, o menino passou a morar com Silvana e Bianca, de modo que a criança foi se tornando filho da jovem até viver definitivamente com sua nova família.

Em outra casa, encontramos Joane. Ela tem quarenta e dois anos e se declara negra de cor. Conta que começou a cuidar de criança muito menina: "desde que me
5| "Ajuda" é uma categoria digna de reflexão ao longo da análise. Nesse sentido, vale pensar de que forma o termo condensa dádivas e pagamentos em dinheiro que ocorrem também em outros contextos etnográficos, a exemplo do trabalho de Guilherme Passamani (2017) e Adriana Piscitelli (2008a).

6| Trabalhos informais e esporádicos 
entendo por gente". A decisão de abrir sua casa para o recebimento de crianças da vizinhança veio da necessidade de "ajudar em casa" uma vez que seu companheiro recebe apenas um salário mínimo como zelador de uma igreja evangélica. Joane é evangélica e explica que cada criança que chegou ali: "foi porque Deus mandou". Ela chama sua casa de "escolinha" e deu o nome de "Filhos do pai" para sua atividade.

Além das crianças que cuida, em sua casa moram seus quatro filhos, duas meninas e dois meninos. Esses últimos possuem deficiência. Durante a infância das crianças, os irmãos tiveram muitas crises de epilepsia. Joane relembra que nessa fase seus filhos precisaram de muitos médicos - fonoaudiólogos, ortopedistas, neurologistas -, mas as dificuldades de receber atendimento médico adequado na rede pública de saúde se arrastaram por muitos anos, e devido à lentidão dos serviços de saúde as crianças ficaram com sequelas para vida inteira. Os dois irmãos são gêmeos e possuem lesões neurológicas que impedem a fluência da fala e muitos movimentos corporais. Assim como na casa de Silvana, as filhas meninas ajudam nas tarefas de cuidado com as outras crianças, dando banhos, comida e realizando brincadeiras.

Joane foi uma das interlocutoras que contou sobre o medo de receber fiscalizações do Estado. Explicou que sua casa não tem "boas condições" para acolher as crianças e que, por isso, vive com receio de que o conselho tutelar possa bater em sua porta, ou "qualquer outro órgão do governo". Nas vezes em que falou sobre seu medo, mostrou-me as condições físicas da casa, narrando o que identificava como sendo defeitos de sua residência: paredes descascadas, umidade, restrição de água, mistura de eletrodomésticos no mesmo ambiente, além da convivência com crianças "que não são normais", como ela explica.

Dadas as condições de pobreza e adversidade no acesso aos cuidados de crianças por parte de algumas famílias, Joane algumas vezes cobra preços diferenciados para mulheres em situações de dificuldades. Essa negociação flexível acontece em todas as casas, mediante algumas necessidades identificadas e negociadas entre mulheres mães e as donas das casas. Crianças que são irmãs, ou mães identificadas como solteiras e sozinhas podem receber alguma flexibilidade em preços e pagamentos. Com isso quero enfatizar que o acesso ao cuidado nessas casas é feito a partir de ajustes e negociações feitas caso a caso.

Ao falar dos medos que sente, Joane lembrou uma ocasião em que uma mulher da vizinhança contou sobre fofocas: "que estão rolando com seu nome no morro". Ela explica que essas desavenças ocorrem quando as pessoas discordam de posturas que julga como corretas. Um exemplo dessa situação se referia a uma fofoca sofrida como forma de retaliação por parte de uma mulher que lhe devia dinheiro. A moça não conseguia arcar com as despesas do mês relativas ao cuidado de seu filho, fato que desencadeou a retirada da criança dos cuidados da casa. Joane vez em quando cobrava a moça pelos seus serviços. Nessa situação, a mulher espalhou fofocas sobre a existência de preços diferenciados cobrados às mães. 
Como Joane elucida, tais desavenças podem "cair na boca do povo" e serem convertidas em acusações sobre as condições de precariedade das casas e supostas negligências. A mulher espalhou pelo morro que as crianças ficavam sozinhas na companhia de crianças "doentes" (seus filhos com deficiência). Joane explicou que essa fofoca podia chegar na forma da acusação de "pedofilia" ao comércio de drogas local, fato extremamente perturbador dado a insinuação complexa que tal ameaça representa.

Em certa ocasião, acompanhei uma situação de conflito intenso envolvendo Joane e uma mãe que deixava seus filhos no turno da noite para estudar para o vestibular. Joane havia decidido que o tempo que as crianças passavam sob sua guarda estava excessivo, e por esse motivo disse que não poderia mais ficar com elas no turno da noite: "já pensou se todo mundo aqui resolve estudar?", disse repreendendo a mulher. Esse evento fez com que a mãe deixasse as crianças na rua brincando enquanto se dedicava aos estudos, fato que suscitou fofocas da vizinhança sobre seus filhos que foram considerados "largados". No limite, uma mulher mãe que decide agenciar os cuidados de seus filhos junto ao projeto de escolarização foi enquadrada como "egoísta" e "irresponsável" pela moralidade local.

Em outra casa, encontramos Neli, uma mulher de sessenta e nove anos que se declara negra de cor. Ela cuidou de três gerações de pessoas. Algumas vezes, presenciei pais que também foram cuidados por Neli quando eram crianças vindo ao seu portão buscar os filhos. Durante as férias, Neli chega a receber cerca de quinze crianças. $\mathrm{O}$ trabalho que realiza é a principal fonte de renda da família, de modo que consegue sustentar duas filhas adultas que estão desempregadas. Sua casa possui um grande trânsito de chegadas e saídas. Pelo fato de a casa viver movimentada, algumas pessoas na comunidade comentam que ela "ganha muito dinheiro com criança". Essa afirmação também é veiculada na creche por parte das profissionais de educação.

Em sua casa, entendi que a questão da partilha de bens sociais não se limita às crianças, mas envolve outros recursos sociais vitais para a continuidade da vida. Neli e sua vizinha dividem o acesso à água entre as suas casas. O complexo do São Carlos sofre com a escassez de água, que é resultado da ineficiência das políticas de saneamento básico em regiões de favela na cidade. A água é compartilhada por uma mangueira que sai da casa de Neli e se estende até a casa de sua vizinha. As crianças explicaram que a vizinha tem ciúmes do trabalho que Neli desenvolve, pelo fato da casa viver "cheia de criança". Essa abundância de crianças na residência é lida socialmente como fartura, por isso se referem a Neli como uma pessoa muito próspera.

Em todas as casas que frequentei, as mulheres buscam oferecer soluções a problemas inusitados que falam de situações de vulnerabilidade. Crianças que por algum motivo não possuem uma fralda ou não trazem a comida do dia são sanadas em suas urgências a partir dos gestos de partilha das mulheres. Duplas de irmãos que precisam ser cuidados recebem descontos no valor do pagamento mensal. Crianças que passam por algum tipo de situação familiar de conflito, como em situações em que 
casais estão em dinâmicas de violência ou em caso de morte de familiares recebem maiores atenções, sendo amparadas por essas mulheres. Ressalto esses feitos no sentido de registrar que há sempre algo a mais que é realizado. Esse algo a mais pertence a uma espécie de superávit das relações de cuidado, algo que diz respeito às ações "fora" desse trabalho, partes não contabilizadas como tal e que mesmo assim são incorporadas como um dever a ser cumprido (Weber, 2009). Esses excedentes não contabilizados fogem a uma economia utilitarista das relações sociais, ao mesmo tempo em que materializam as bases nevrálgicas do trabalho de cuidado. Uma atividade multifuncional e diversificada que, apesar de envolver uma reflexividade moral, um engajamento emocional e um trabalho corporal, é rebaixada socialmente do ponto de vista político e econômico.

Todas essas mulheres trabalham no registro da "ajuda" nos quais determinados pagamentos monetários, apesar de importantes, não consistem na única forma de retribuição dos serviços ofertados. Confianças, favores e solidariedades devem ser construídas e sustentadas a todo o momento, a exemplo das vizinhas que, mesmo diante de situações de conflito pessoal, apostam na partilha da água.

A existência dessas casas nas comunidades periféricas diz respeito a uma prática de longa duração histórica. Em outras palavras, é graças a essas formas de acolhimento que gerações de trabalhadores acessam uma mobilidade social, com a possibilidade de fazer uma família em um contexto no qual a gestão dos cuidados nas classes populares volta e meia é tema de escrutínio público. Em termos estruturais, há um imaginário nacional que remete a valores sobre tipos ideais de família considerados signos de modernidade. Ainda que ficcionais, esses valores informam sobre modelos normativos de cuidados e desenhos de políticas públicas que inspiram comportamentos modelares de indivíduos e populações: o casal nuclear, a gravidez planejada, proles reduzidas, a obrigação de ter uma casa e um trabalho como condição para início da vida reprodutiva. Tais elementos figuram como representações de família, ao mesmo tempo em que organizam expectativas relativas às políticas públicas de Estado. ${ }^{7}$ Esses elementos fazem parte de uma ideologia da gravidez planejada, que, por sua vez, opera de modo extremamente normativo quando não corresponde à multiplicidade de trajetórias sexuais, reprodutivas e configurações familiares que fogem dessa fabulação.

No contexto da elite e das classes médias brasileiras, os elementos considerados como signos de modernidade narrados acima, só podem ser sustentados por meio de um investimento pesado em modelos privatizados e pessoalizados de guarda de crianças, ou seja, dependentes do trabalho de mulheres pobres, negras e racializadas que realizam os serviços de babás, empregadas domésticas, faxineiras e diaristas. Esse é um modelo de "reprodução estratificada" que distribui de forma desigual as possibilidades das famílias de ofertar afeto, segurança, tempo e proteção aos seus próprios filhos (Colen, 2007). Vale ressaltar que muitas das mulheres que precisam deixar seus filhos nas casas de "tomar conta" e nas creches trabalham como empregadas
$7 \mid$ Conforme indicam os estudos de Edlaine de Campos Comes e Luiz Fernando Dias Duarte (2008) e Claudia Fonseca (1995b) sobre a temática do parentesco, os agenciamentos familiares das classes trabalhadoras implicam pensar relações densas de territorialidade e parentalidade nas quais redes de interdependências formam os sujeitos como pessoas morais. 
domésticas, babás, isto é, ocupações subalternas e terceirizadas. Logo, olhar para a centralidade dessas casas ao lado da precariedade do serviço público oferecido na educação infantil é atentar para as forças de reprodução de desigualdades de gênero, raça, classe e território que modulam possibilidades de fazer família, ter experiências de infâncias e produzir mobilidades sociais.

\section{O DIREITO COMO SUPLÍCIO: AS CRECHES COMO ESPAÇOS DO CUIDADO E EM MEIO A ESCASSEZ}

Numa tarde de trabalho de campo na creche, uma profissional me contou sobre o dia que foi caminhar "dentro" da favela. Como relembrado por ela, apesar de trabalhar em uma instituição que se situa na entrada do morro, ela nunca havia caminhado pela comunidade. Contou que nesse dia ficou perplexa com tanta "desorganização". Descreveu sua caminhada com muita riqueza de detalhes: roupas para fora das janelas, lixo na porta de casa, fios elétricos embaralhados, construções inacabadas, vendas que oferecem de tudo, e outros mil e um detalhes eram narrados como uma experiência impactante. Ao comentar sobre esses aspectos, ela gesticulava e tentava explicar o "horror" e a "confusão" encontrada no trajeto percorrido, ao mesmo tempo em que ponderava sobre as dificuldades que a população passava e que de alguma maneira justificavam o suposto "caos".

Ao fim, ela conclui que se tratava de uma incompetência dos pobres para organizar o seu próprio espaço. Mais tarde, entendi que uma visão semelhante é partilhada também por alguns moradores. Ao discorrer sobre o acúmulo de lixo no valão situado em uma região central do Morro da Mineira, o Presidente da Associação de moradores explicou que não adiantava limpar o espaço, pois, em suas palavras, os moradores "não têm educação e no outro dia jogam lixo de novo", contando que nessas circunstâncias: "o problema do lixo é do próprio morador". Outros moradores, ao comentarem sobre a situação do lixo, também reforçam essa visão e enfatizaram o papel que cada sujeito possui na administração dos seus descartes.

O estereótipo da confusão dirigido às favelas e aos seus moradores não é algo novo e faz parte de uma perspectiva histórica que considera esses territórios como lugares da desordem (Birman, 2008). No contexto da pesquisa realizada nas creches, observa-se que parte desse imaginário é atribuído às práticas das mulheres que "tomam conta" de crianças, mesmo a despeito do seu papel fundamental na criação de gerações de trabalhadores. Além da ideia da confusão e desorganização atribuída à população favelada, há uma atribuição de responsabilidade aos sujeitos acerca de diversas mazelas sociais.

Da política aberta às negociações e às especificidades de cada família, passamos para uma atuação em que o atendimento às crianças se faz por meio de uma instituição mediada através de regras e formalidades. Estamos diante de um espaço atravessado 
por normas e procedimentos específicos: horários de entrada e saída, critérios de acesso, princípios de organização do trabalho, condutas de segurança, proteção, higiene e diretrizes pedagógicas de educação. Contudo, mesmo nesse ambiente regulado por uma quantidade significativa de normas, há a presença de elementos de precariedade que não desfazem a compreensão dessa entidade como o lugar mais adequado e organizado na responsabilidade pela educação infantil. No decorrer do trabalho de campo, observei como a creche é um espaço narrado como ideal ao bom cuidado das crianças e, ao mesmo tempo, é um lugar com aspectos de fragilidade do ponto de vista das instalações físicas, dos recursos humanos e dos mecanismos de gestão do equipamento público. Essas dimensões apontam para uma série de vulnerabilidades relativa às condições gerais do tipo de educação infantil que é ofertada para a população moradora de território periféricos.

Dada a responsabilidade com o tipo de público que atendem, um conjunto de dispositivos de vigilância cerceia a ação das profissionais, a exemplo das câmeras em sala de aula ou das exigências de higienização do ambiente. Ao longo da temporada da pesquisa de campo, entendi que esse espaço comporta uma sobrecarga de trabalho significativa por parte de toda equipe profissional. Logo, guardadas as devidas proporções, veremos como a visão sobre uma desordem projetada para fora da favela deve ser administrada dentro da instituição com o objetivo de manter a imagem de ordem e lisura atribuída a esta, uma vez que a impressão de ordem é fundamental para a preservação da imagem do Estado como uma entidade coesa.

Um dos principais problemas que atingem as creches públicas diz respeito ao acesso às vagas nas instituições. Para ingressar em uma unidade de educação infantil é necessária a participação em um sorteio público realizado anualmente pela prefeitura. Além do sorteio, as pessoas também são avaliadas diante de critérios assistenciais que pontuam determinadas vulnerabilidades: familiares presos, gravidez na adolescência, familiares com doenças crônicas, entre outros aspectos que contam como prioridades na disputa por uma vaga.

Para uma estimativa geral, a lista de espera por vagas em cada unidade de creches pode chegar a duzentas crianças por unidade. A lista é um documento que materializa a devolução da responsabilidade estatal do cuidado às famílias e, ao devolvê-la, o Estado se isenta de uma obrigação constituída na lei. A restituição da responsabilidade às pessoas que não conseguem as vagas será agenciada no tempo da "viração", em muitos casos, nas casas de "tomar conta", nos quais os ajustes e resistências serão diariamente produzidos. Esse elemento é fundamental para estabelecer uma familiaridade complementar entre as casas e creches, pois é a partir dessa falta que as casas são indicadas pelas profissionais, mesmo a despeito da informalidade que cerceia essa prática.

Acessar uma creche pública significa aumentar as possibilidades de ascensão social, econômica e profissional de mulheres e famílias pobres. Além de permitir que 
as crianças sejam alimentadas e educadas, a instituição favorece o acesso a uma série de outros recursos sociais alvos de intensa disputa nas camadas populares: cadastro no bolsa família, vacinação, cartão carioca, acesso ao exame de DNA, entre outros recursos. Ademais, cabe salientar que a creche é historicamente uma reivindicação clássica de movimentos feministas. No Brasil, durante as décadas de 1970 e 1980 foram produzidas importantes lutas pelo direito à creche com forte protagonismo do movimento feminista entre outros movimentos sociais, como os setores sindicalistas e de trabalhadores. O slogan "O filho não é só da mãe" foi um dos gritos do movimento nacional por creches e mobilizou conquistas importantes registradas na constituição de 1988, a exemplo da consolidação das creches públicas como um direito fundamental, ao lado da licença paternidade e da ampliação da licença maternidade para cento e vinte dias. Portanto, a luta pela garantia desses espaços envolve tanto reivindicações feministas por espaços coletivos de cuidados, como do movimento pelos direitos das crianças por educação.

No contexto da creche, a presença de elementos de escassez fala sobre a precarização das condições de trabalho que as profissionais atuam. A sobrecarga de tarefas e funções é um elemento produtor de tensão nas rotinas das professoras, diretoras, auxiliares de cozinha e limpeza. O ritmo de trabalho intenso impacta no tipo de cuidado que é oferecido às crianças. A falta de professores na rede decorre da falta de investimentos em concursos públicos na área, acarretando na situação em que turmas idealizadas para funcionar com duas professoras e duas auxiliares tenham apenas a metade desse quadro. Na parte administrativa, as diretoras acumulam funções assistencialistas com educativas, de modo que a gestão da instituição se faz entre as tarefas rotineiras impostas pelos quadros superiores, o cadastro das famílias em benefícios sociais, encaminhamentos para exames de DNA, supervisão dos pedidos de alimentos, além das questões cotidianas que surgem no dia a dia de trabalho. Soma-se a isso a resolução de problemas da instituição com o "dinheiro do próprio bolso", como a realização de vaquinhas para custear serviços de consertos, rateio de internet, falta de materiais de limpeza ou mesmo coleta de lixo.

Essa intensidade emocional do trabalho de cuidado está muito presente na atmosfera sonora da creche. Durante as primeiras semanas do trabalho de campo, saía das tardes da instituição com fortes enxaquecas. Com o passar do tempo, acabei me acostumando com essas manifestações a ponto de naturalizá-las. O tema voltou a chamar minha atenção quando, meses mais tarde, observei que muitas profissionais consumiam remédios para dores de cabeça com frequência. Além desse tipo de medicamento, são constantes as queixas sobre estresse, cansaço e outras questões relativas à saúde mental. Quero dizer que apenas após a passagem de um tempo considerável na instituição me dei conta de que o barulho e o som institucionais são indicadores das condições de precariedade e exaustão com as quais profissionais e crianças convivem. 
As salas das unidades possuem janelas pequenas, que muitas vezes devem permanecer fechadas devido ao risco de disparos oriundos de tiroteios provocados pela ocupação policial e militarizada no território. Numa sala pequena com cerca de dezoito crianças, o volume sonoro dos gritos, falas e brincadeiras vão se avolumando a ponto de produzir a exaustão física e mental das profissionais. O som ruidoso e estridente do ambiente institucional não se constitui como um mero desajuste, mas trata-se de um agente que fala das condições emocionais e de trabalho compartilhadas pelas crianças e pelas profissionais. Estamos diante de uma atmosfera sonora que literalmente grita a sobrecarga desse tipo de trabalho emocional intenso e fatigante.

Este aspecto complexifica as fronteiras entre zonas de margem e práticas estatais, no sentido de que identificamos a presença de práticas dissidentes em contextos projetados como hiper normativos. Elementos de "desordem" atribuídos às alteridades, àquilo que os outros fazem e/ou deixam de fazer, podem ser observados no interior das instituições.

Nas creches públicas, as profissionais se dividem em formações e cargos diferenciados. Apesar dessas diferenças, todas são oriundas das camadas pobres da cidade e muitas são moradoras de territórios periféricos. As profissionais ingressaram no serviço público de educação infantil com o objetivo de ter algum tipo de estabilidade financeira, ou mesmo de acessar a sonhada carteira assinada, no caso das funcionárias terceirizadas. Essas informações são importantes para explicar que, por mais que estejam situadas em posições sociais diferentes dos usuários da instituição, as profissionais e as mulheres atendidas são atravessadas pela demanda do cuidado das crianças numa realidade em que o acesso à educação infantil é extremamente disputado. Do ponto de vista das condições sociais e econômicas entre profissionais e famílias, há uma proximidade das questões enfrentadas relativas aos desafios do cuidado e do ônus da reprodução distribuído entre as famílias, ainda que esta proximidade não desfaça as hierarquias de poder e distância social que perpassam essa interação.

No cotidiano das creches, existem fortes moralizações em relação aos comportamentos femininos que não atendem às expectativas do que é considerado como uma boa forma de exercício de maternidade. Essas indicações estão presentes em apontamentos que discorrem sobre exemplos de mulheres que são alvo de crítica local: "a mãe que chega de biquíni e suja de areia para pegar o filho na hora da saída", "a mãe que não olha a mochila da criança", "a mãe nervosa", "a mãe que fica doida pra largar na creche", "a mãe que não tem apego", entre outras passagens, são evocações que assinalam a fertilidade de determinados discursos em regular e projetar imagens congeladas sobre performances femininas consideradas inadequadas.

Essas marcações possuem efeitos dramáticos nas dinâmicas de relação intra gênero que, diante dessas comparações, hierarquizam mulheres inseridas no mesmo contexto de disputa por recursos sociais. Em geral, as referências aparecem de forma 
conectiva, na relação com outras histórias, que se colam a partir do enunciado: "Igual essa aqui... a mãe que abandonou". Esse enunciado cumpre uma função de caráter sociológico e antropológico: "Igual essa aqui" é a demonstração empírica de que o problema social sobre o qual as pessoas confabulam tem materialidade e permite acessar as carnes morais do cuidado, ao mesmo tempo em que fornece elementos na produção de estigmas sobre determinadas mulheres consideradas desviantes ou "erradas".

Durante o cotidiano de atendimento nas creches, as profissionais operam com uma dupla moralidade em relação às casas de "tomar conta". Da mesma forma em que indicam esses espaços para a guarda das crianças que não conseguem ser atendidas, destacam os elementos de precariedade e vulnerabilidade presente nesses espaços. Segundo as narrativas das profissionais, as casas não são lugares adequados para o cuidado das crianças, uma vez que não possuem uma boa estrutura física, não apresentam fiscalização da comida, tampouco uma preocupação pedagógica com a educação das crianças: "lá, elas ficam largadas". Também mencionam o fato de as crianças permanecerem juntas em grupos de idades misturados, e de assistirem TV de forma excessiva. Além desses aspectos, um comentário recorrente diz respeito às cuidadoras, vistas como mulheres que "ganham muito dinheiro com criança". A atividade de cuidado nas casas é, assim, alvo de fofocas e rumores sobre um suposto rendimento financeiro significativo, que, num contexto de pobreza, atiça os imaginários locais sobre lucros e oportunidades de trabalho rentáveis. A imagem do programa Bolsa Família é um significante dessas formas de elucubração social, pois está presente em discursos que falam sobre sujeitos identificados não apenas como dependentes, mas como pessoas que gostam e têm prazer de viver na dependência.

Essas falas e apontamentos possuem um peso particularmente perverso quando muitas famílias, apesar de precisarem acionar as casas, apontam a creche como um espaço preferencial ao cuidado dos filhos, mesmo a despeito das críticas existentes. Logo, esse jogo de acusação e aproveitamento consegue ser ainda mais pungente diante do fato de que, ao mesmo tempo em que essas as casas são escrutinadas, elas também são indicadas para atender o fluxo de crianças da lista de espera, assim como solicitadas pelas famílias enquanto estas anseiam adentrar nas malhas da proteção estatal.

Nesse sentido, cabe retomar as palavras de Vera da Silva Telles (2010), quando extrai reflexões sobre o urbano a partir das formulações acerca dos ilegalismos cunhadas por Michel Foucault. A autora relembra que a "gestão diferencial dos ilegalismos" se dedica a entender menos a forma como a lei é obedecida e mais sobre a forma como as leis operam, de modo a "riscar os limites da tolerância, dar terreno para alguns, fazer pressão sobre outros, excluir uma parte, tornar útil outra, neutralizar estes, tirar proveito daqueles" (Foucault, 2006: 227). Nesse sentido, guardo a expressão "tirar proveito daqueles" como uma fórmula para entender uma das maneiras essenciais pelas quais as administrações públicas se relacionam com as casas: tirando proveito delas. 
É fundamental entender que falas, linguagens e discursos instauram legitimidades, desqualificam determinados sujeitos e modulam comportamentos vistos como justos ou infelizes. A partir desses atos e linguagens acionadas pelas profissionais, há uma projeção de estereótipo para mulheres vistas como usurpadoras, tanto aquelas que "fazem filhos demais", quanto aquelas que "cuidam dos filhos dos outros", conforme aludem as categorias nativas.

Esses jogos de elaboração entre espaços e práticas mais legítimas do que outras falam do que Adriana Vianna e Laura Lowenkron analisam como "o duplo fazer do gênero e do Estado" (2017). São jogos que produzem enquadramentos generificados, e permitem que a escassez da gestão estatal seja explicada a partir de um suposto comportamento feminino hipersexualizado. É preciso afirmar que, mesmo diante da informalidade das práticas, as casas estão colaborando para suprir a ineficiência do poder público, e, nesse sentido, a estabilização de lugares precários faz parte do que Timothy Mitchell chamou de um "efeito de Estado" (2006). De acordo com o autor, a aparente distinção entre Estado, Economia e Sociedade como coisas separadas serve para manter uma dada ordem econômica e política, extremamente útil na fruição de recursos financeiros e sociais. Esses processos são eficientes para diluir tarefas, delegar orçamentos, e atribuir responsabilidades, obrigações e gestões. Essas fronteiras dizem respeito aos expedientes e procedimentos institucionais que visam estabilizar determinados limites entre poderes, a exemplo dos âmbitos do executivo, legislativo, judiciário e da esfera entendida como sociedade civil. Com base na sua análise, podemos dizer que, ao criar uma apartação entre as instituições e as casas, ocorre uma projeção da entidade pública como lugar mais capacitado em detrimento de outros, apontados como menos capazes. Simultaneamente, a instituição se aproveita da precariedade dos outros - precariedade esta que, por sua vez, está intimamente constituída na interface com as administrações - para suprir, amortecer ou minorar uma demanda que ela própria não é capaz de atender.

Nesse sentido, "o Estado", da forma como é narrado nas falas, seja dos moradores da favela, seja dos agentes que atuam nas malhas institucionais, não está "ausente", mas se revela como sendo a própria ausência que cria, sustenta e se aproveita destas formas particulares de "viração" e informalidade. Por este motivo, é preciso enfatizar que existe uma agência poderosa na chamada "ausência de Estado", que não deve ser entendida como falta ou incapacidade, mas como uma ação consciente e dotada de efeitos concretos na vida das pessoas. A "ausência de Estado" faz determinadas coisas acontecerem, de modo que este elemento supostamente "invisível", desencarnado e desfigurado é a base motriz das "virações", das redes de ajuda e das situações de precariedade atribuídas tanto às casas como às maternidades desviantes. $\mathrm{O}$ argumento expresso aqui consiste em significar que quando as ações de Estado não fazem, elas estão fazendo, imiscuídas nos silenciosos, solitários e enérgicos processos da vida 
cotidiana, muito palpáveis nas formas como as pessoas vão se ajeitar, arrumar e fazer seus mundos ${ }^{8}$.

Nesse sentido, as creches, como um "Estado que funciona ao lado das casas", não aponta somente para uma distinção entre dois âmbitos autônomos, mas é lócus privilegiado para acompanhar o que este "Estado" produz como alteridade, ao enquadrar mulheres como figuras aglutinadoras do excesso comportamental social e sexual. Se por meio das falas cotidianas as profissionais dizem que as casas não são lugares ideais para guardar crianças, na prática, "a creche indica a casa", apesar de refutar este espaço como adequado. É, portanto, a partir da sua própria precariedade e incapacidade de atender a uma demanda específica que a creche se torna um aparato fundamental para a preservação da imagem do Estado. Dessa forma, a ideia de um Estado provedor é mantida e reificada, "O Estado que cuida das pessoas" e/ou "dos filhos dos outros", mesmo quando essa entidade depende do trabalho de mulheres em condição de subalternidade.

Logo, mediante uma falsa imagem de Estado provedor, esses discursos reforçam a ideia de que existe uma responsabilidade assumida pelo governo. $O$ trabalho realizado nas casas amortece a inação da creche, daquilo que esse dispositivo não consegue "tomar conta", sendo ora um espaço rechaçado, ora indicado, a depender de cada ocasião. Este aspecto aparentemente paradoxal se desfaz em sua contradição quando entendemos que aqui repousa uma das maneiras elementares e primordiais de se fazer práticas de Estado, a saber, no rechaçar a matéria viva da qual ele depende para se produzir como ente supostamente autônomo e superior.

\section{CONSIDERAÇÕES FINAIS}

Ao analisar as trajetórias de mulheres que migram de países economicamente periféricos para regiões mais ricas e industrializadas, a socióloga Arlie Hochschild (2000) desenvolve o conceito de "cadeias globais de cuidado". Em busca de emprego remunerado, mulheres pobres e racializadas deixam seus filhos aos cuidados de outras mulheres pobres para trabalhar na casa de famílias estrangeiras que necessitam de força de trabalho reprodutiva. Esse fluxo migratório desvela redes de interdependência nas quais o cuidado de alguns é ofertado mediante a precarização e subalternidade de outras famílias. Trata-se de redes transnacionais que envolvem dinheiro, atenção, trabalho reprodutivo e mobilidade social articuladas à experiência de raça, etnicidade, sexualidade e gênero.

A partir da proposição de Hochschild, ao analisar a complementaridade entre creches e casas, constatamos a presença de cadeias locais de cuidados relativas aos agenciamentos produzidos entre as populações mais pobres da cidade na interface com as administrações de Estado. A maioria das mulheres que deixam seus filhos nas casas e creches públicas atua no âmbito do serviço doméstico como babás, empregadas, 
faxineiras e diaristas, além de outras ocupações no comércio e no setor de serviços. Logo, esses são lugares cruciais para identificar a centralidade do trabalho reprodutivo de cuidado na exploração das condições de vida das periferias em circunstâncias de proximidade e desigualdade social.

A obrigação constitucional de cuidado com as crianças é alvo de questionamentos sobre os deveres da atuação do Estado. A depender de como cada gestão governamental lide com essa causa pública, os investimentos em creches implicam discussões sobre os limites da ação do Estado e dos custos sociais e econômicos envolvidos na manutenção dessas instituições. Diante da gigantesca demanda por vagas em creches públicas, a presença das casas é fundamental para $o$ atendimento de famílias pobres. As casas permitem compreender uma forma de governo que se faz a partir da ausência. Nessa perspectiva, governar é não fazer. A existência das "listas de espera" que são fixadas nas paredes de todas as creches públicas é a marca do governo por meio da inação. É sobretudo um indicador de que a responsabilidade do cuidado foi devolvida aos familiares. Uma vez nessa lista, serão eles que deverão improvisar sua "viração" e suas redes de "tomar conta". No entanto, cabe identificar que o tempo da espera não se constitui num tempo morto, mas trata-se de um elemento profundamente ativo que fala de uma agência intensa dos atores, das hesitações e arranjos que devem ser feitos afim de dar conta da urgência do cuidado (Vianna, 2015). É, nesse sentido, um tempo sobretudo generificado, posto que será resolvido pela rede majoritariamente feminina que torna o "tomar conta" possível (Fernandes, 2018).

Enquanto lugar supostamente ordenado, a creche é feita de irrupções de "desordem" presentes na sua atuação. A "desordem" produzida no espaço institucional é reconhecida e narrada como legítima e, desta maneira, autorizada e isenta. Podemos, pois, nos perguntar: que espécie de efeito mágico é operado nas malhas da ação de Estado que faz com que práticas similares sejam vividas de maneira maldita para uns e legítima para outros? Creio que a discussão apresentada aqui, aponta para de que forma os processos de "fazer Estado" se fazem mediante aos processos de desfazer as boas condições de vida das populações.

Diante da escassez da demanda pelo cuidado nesses territórios, os discursos sobre mulheres que "fazem filhos demais" atravessam ambos os espaços e possuem tremenda força de ação. Entretanto, mais do que atentar para polos potencialmente antagônicos, busquei destacar um espaço intersticial no qual ambos os lugares e suas formas de relação coexistem e colaboram na produção de certas fronteiras. A gestão do lixo, a partilha da água e o cuidado compartilhado das crianças falam de responsabilidades estatais que são convertidas e internalizadas como questões individuais de cada morador. Na lógica da transferência de responsabilidades, cada família deve se esforçar para superar um conjunto de adversidades que correspondem a dinâmicas mais amplas de exploração. 
A partir da ação das casas, as crianças crescem graças aos esforços múltiplos que são empreendidos nas redes de ajudas. Logo, não é difícil dimensionar o papel precioso que as casas de "tomar conta" possuem nessa conjuntura. São elas, mulheres periféricas, donas de casa, que, por intermédio do trabalho informal, conseguem atender à demanda pelo cuidado de crianças. Contudo, mesmo diante do profundo impacto que esse trabalho possui na demanda pelo cuidado nas classes populares, as mulheres não recebem qualquer auxílio do governo, mas, ao contrário, realizam as atividades na zona da informalidade, com todos os custos emocionais envolvidos. A precariedade das condições de trabalho se soma às ameaças sobre ilegalidade, concretizadas no receio em medos receber uma visita do governo, do conselho tutelar, além da sujeição às fofocas e rumores da moralidade local. Assim, pelo fato dessas atuações serem relegadas ao trabalho informal, o trabalho exercido durante anos por essas mulheres não possui nenhum tipo de benefício social, previdenciário ou qualquer outra forma de suporte.

No contexto das discussões ocorridas na década de 80 sobre a política de creches, Fúlvia Rosemberg (2003) aborda a tentativa de regulamentação destes espaços pelos órgãos de Estado e chama atenção para a permanência destas práticas enquanto realidade de diversos contextos regionais:

Este sistema de guarda da criança pequena não é novo, nem específico ao Brasil e a países desenvolvidos. O que tem sido novo é a divulgação do programa em nosso meio com a solução alternativa do Estado expandir o número de vagas em creche (2003:69).

As críticas dirigidas à modalidade da "creche familiar" se demonstram extremamente atuais no contexto desta pesquisa.

Tanto no contexto da década de 80, como no atual cenário, são apontadas diversas desordens nos modos de criar realizados nas casas. As principais críticas se referem ao fato de que estas se dedicam à função exclusiva da "guarda", em detrimento da preocupação com o caráter "pedagógico e educativo". Outra crítica se concentra na "confusão" entre os mundos da família, da casa, e da instituição, na qual "casa e família são conceitos que não se confundem" (ibid.: 74). A creche familiar seria assim desenhada como este espaço de "ambiguidades" no qual as pretensões familiares se mesclam a pretensões institucionais, consideradas incompatíveis. Tal "ambiguidade" seria, para Rosemberg, própria de uma outra confusão do próprio Estado Brasileiro, que estaria "perdido" entre a necessidade de compartilhar a responsabilidade do cuidado com as famílias e, ao mesmo tempo, tomar como responsabilidade política o seu papel neste compartilhar. A autora afirma que "a creche domiciliar no contexto de atuação do Estado seria uma tentativa de atuação entre o velho e o novo" (2003: 76), em uma alusão ao que seria um ajuste precário entre "estratégias de vida" da classe popular com a modernização do Estado Brasileiro, 
representada, neste contexto, pela proposta de fortalecimento da política de creches. É importante salientar que a busca pela delimitação de fronteiras rígidas entre a identidade da creche em contraposição às casas se faz na necessidade de posicionarse em outras discussões candentes na época, que giravam em torno da ameaça das creches se colocarem como "substitutas ao cuidado materno". Tais debates não foram banais e mostram que o dever de cuidar se atualiza na fervorosa disputa triádica entre famílias, "papel materno" e Estado.

Passadas quase três décadas da tentativa de incorporação destas casas pelas administrações públicas, a cobertura das creches continua sendo exercida a conta gotas. Entretanto, o jogo de forças entre as ações de Estado e as famílias pobres se adensou; famílias são vistas como "aproveitadoras" dos serviços das creches, mães são vistas como "irresponsáveis" e pobres são vistos como produtores de filhos na "hora errada". A imagem de mulheres apontadas como usurpadoras dos serviços da creche reifica o estereótipo feminino da mulher golpista, muito presente nas discussões populares que criticam o Programa Bolsa Família. Nessa perspectiva, serviços públicos registrados como um direito devem ser batalhados em trajetórias de suplício. Enquanto bens fundamentais à reprodução social da vida humana, creches e suportes de apoio são requeridos mediante peregrinações e martírios cotidianos, num caminho que atualiza as ideias monoteístas e cristãs de sacrifício, dor e pecado no âmbito da sexualidade e reprodução femininas.

Nas casas, compreendemos o apelo poluidor que determinadas maternidades possuem: "a mãe que não traz a comida", "a mãe que abandona", "a mãe que passa muito tempo longe do filho", são todas alegorias que falam de uma certa maneira correta e boa de ser uma mãe "de verdade". Tais representações fazem parte do conjunto de estereótipos sobre mulheres negras, racializadas e pobres que a partir de fortes enquadramentos de gênero, sexualidade e raça aludem a mulheres negras, pobres e moradoras de favela como de sexualidade quente e descontrolada (Carneiro, 1995; Moutinho, 2004; Corrêa, 2007). Esse jogo de insinuações e acusações possui o efeito de desumanizar a maternidade negra e pobre, uma vez que retiram a legitimidade de mulheres nos processos de fazer família, parir, cuidar e ser mãe. Quero salientar que tais alusões não se reduzem a meros lapsos e retóricas discursivas, mas significam formas de governar corpos femininos, distribuir legitimidades, sexualizar condutas, consentir violências, negar direitos e perpetuar racismos generificados.

No cenário contemporâneo, se antes as administrações públicas pensavam em incorporar estas mulheres de alguma forma, fosse mediante incentivos, cursos de capacitação ou financiamento público, hoje em dia a gestão municipal ignora a presença das casas e age como se elas não existissem. Enquanto a ação pública finge que as donas da casa não fazem o que elas fazem, as profissionais das creches, que são "o Estado na ponta", continuam indicando o trabalho de mulheres da vizinhança na terrível batalha por recursos sociais em que se tornou a disputa por vagas públicas. 
Camila Fernandes é pós-doc no Programa de Pós-Graduação em Antropologia Social (PPGAS/MN/UFR]). Doutora em Antropologia Social (PPGAS/MN/UFRJ) e mestre em Antropologia (PPGA/UFF). Pesquisadora do NuSEX - Núcleo de Estudos em Corpos, Cênero e Sexualidades (PPCAS/MN/UFRJ) e do LACED - Laboratório de Pesquisas em Etnicidade, Cultura e Desenvolvimento.

CONTRIBUIÇÃO DE AUTORIA: Não se aplica

FINANCIAMENTO: Bolsista de doutorado (CNPq) e Bolsista de Pós-doutorado (PNPD/ CAPES).

\section{REFERÊNCIAS BIBLIOGRÁFICAS}

AGÊNCIA BRASIL. "Redução no número de filhos por família é maior entre os 20\% mais pobres do país". Link para consulta: https://agenciabrasil.ebc. com.br/geral/noticia/2015-03/reducaono-numero-de-filhos-por-familia-emaior-entre-os-20-mais-pobres

BIRMAN, Patrícia. 2008. "Favela é comunidade?". In: MACHADO DA SILVA, Luiz Antônio (Org.). Vida sob cerco: violência e rotina nas favelas do Rio de Janeiro. Nova Fronteira, Rio de Janeiro.

CARNEIRO, Sueli. 1995. Gênero, raça e ascenção social. Revista Estudos feministas, v. 3, n. 2: 544-552.

CARSTEN, Janet; HUGH-JONES, Stephen. 1995. About the House: Lévi-Strauss and Beyond. Cambridge University Press, Cambridge.

COLEN, Shellee. 2007. "'Like a Mother to Them': Stratified Reproduction and West Indian Childcare workers and Employers in New York". In: GINSBURG, Faye; RAPP, Rayna. (Eds.) Conceiving the New World Order: The Global Politics of Reproduction. University of California Press, Berkeley.
CORRÊA, Mariza. 2007. A babá de Freud e outras babás. Cadernos Pagu, v. 29: 61-90.

D'ANDREA, Tiaraju. 2020. Contribuições para a definição dos conceitos periferia e sujeitas e sujeitos periféricos. Novos estudos CEBRAP, v. 39, n. 1: 19-36. DOI: https://doi. org/10.25091/s010133002020000100055

DAS, Veena; POOLE, Deborah. (Eds). 2004. Anthropology in the Margins of The State. School of American Research Press, Santa Fe.

DEBERT, Guita. 2014. Arenas de conflito em torno do cuidado. Tempo Social, v. 26, n. 1: 35-45.

DEBERT, Guita G.; PULHEZ, Mariana. 2019. Desafios do cuidado: gênero, velhice e deficiência. 2.ed. Campinas, SP: Unicamp.

DUARTE, Luiz Fernando Dias; GOMES, Edlaine de Campos. 2008. Três famílias: identidades e trajetórias transgeracionais nas classes populares. Editora FCV, Rio de Janeiro.

FELTRAN, Gabriel. 2012. Periferias, direito e diferença: notas de uma etnografia urbana. Revista de Antropologia, v. 53, 
n. 2: 565-610. DOI: https://doi.

org/10.11606/2179-0892.ra.2010.37711

FERNANDES, Camila. "O tempo do cuidado. Batalhas femininas por autonomia e mobilidade. In: RANGEL, Everton; FERNANDES, Camila;LIMA, Fátima (orgs.). 2018.(Des) prazer da norma. Rio de Janeiro: Papéis Selvagens, pp. 297-320.

FERNANDES, Camila. 2017. Figuras da causação: sexualidade feminina, reprodução e acusações no discurso popular e nas políticas de Estado Tese de Doutorado em Antropologia, PPCAS-Museu Nacional, Universidade Federal do Rio de Janeiro (UFRJ).

FINCO, Daniela; COBBI, Marcia A.; FARIA, Ana Lúcia. 2015. Creche e feminismo: desafios atuais para uma educação descolonizadora. Campinas, SP, Edições Leitura Crítica; Associação de Leitura do Brasil-ALB; São Paulo, Fundação Carlos Chagas - FCC.

FONSECA, Claudia. 1995a. Caminhos da adoção. São Paulo: Cortez Editora.

FONSECA, Claudia. 1995b. "Amor e família: Vacas sagradas da nossa época”. In: RIBEIRO, Ivete; RIBEIRO, Ana Clara T. (Orgs.). Família em processos contemporâneos: Inovações culturais na sociedade brasileira. Loyola, São Paulo, pp. 69-89.

FOUCAULT, Michel. (2005). Em defesa da sociedade. Curso no Collège de France (1975-1976). São Paulo: Martins Fontes

HIRATA, Helena.; GUIMARÃES, Nádia A. 2012. Cuidado e cuidadoras: as várias faces do trabalho do care. São Paulo: Atlas.

HOCHSCHILD, Arlie. 2000. "Clobal Care Chains and Emotional Surplus Value". In: CIDDENS, Anthony; HUTTON, Will (Eds.). On the Edge Living with Clobal Capitalism. Random House, New York, pp. 130-146.
MITCHELL, Timothy. 2006. "Society, Economy, and the State Effect". InSHARMA, Aradhana; CUPTA, Akhil. (Eds.). The anthropology of the state: A reader. Nova Jersey, Wiley-Blackwell, pp. 169-186.

MOLINIER, Pascale; PAPERMAN, Patricia. 2015. Descompartimentar a noção de cuidado? Revista Brasileira de Ciência Política, n. 18: 43-57. DOI: https:// doi.org/10.1590/0103-335220151802

MORAIS, Gabriel. 2019. "Mais de 36 mil crianças estão na lista de espera por creche no rio". Link para consulta: https://extra.globo.com/noticias/ rio/mais-de-36-mil-criancas-estao-na-listade-espera-por-creche-no-rio-23854493.html

MOUTINHO, Laura. 2004. Razão, "cor" e desejo: uma análise comparativa sobre relacionamentos afetivo-sexuais "inter-raciais" no Brasil e na África do Sul. São Paulo, Editora da Unesp.

PASSAMANI, Guilherme. 2017. “É ajuda, não é prostituição": Sexualidade, envelhecimento e afeto entre pessoas com condutas homossexuais no Pantanal de Mato Crosso do Sul. Cadernos Pagu, n. 51. DOI: http://dx.doi. org/10.1590/18094449201700510009.

PISCITELLI, Adriana. 2008a. Entre as "máfias" e a "ajuda": a construção de conhecimento sobre tráfico de pessoas. Cadernos Pagu, n. 31: 29-63. DOI: https://doi.org/10.159o/ S0104-83332008000200003.

PISCITELLI, Adriana. 2008b. Interseccionalidades, categorias de articulação e experiências de migrantes brasileiras. Sociedade e cultura, v. 11, n. 2: 263-274.

ROSEMBERG, Fúlvia. 2003. Creches domiciliares: argumentos ou falácias. Cadernos de pesquisa, n. 56: 73-81.

SOR]. Bila. 2016. Políticas sociais, participação comunitária e a desprofissionalização do care. Cadernos Pagu, n. 46: 107-128. DOI: https:// doi.org/10.1590/18094449201600460107 
SOUZA LIMA, Antonio Carlos. 2002.

"Introdução: Sobre gestar e gerir a desigualdade: pontos de investigação e diálogo". In: SOUZA LIMA, Antônio Carlos (ed.). Gestar e Gerir: Estudos para uma antropologia da administração pública no Brasil. Rio de Janeiro, Relume Dumará, pp. 11-22.

TELLES, Vera da Silva. 2010. A

cidade nas fronteiras do legal e ilegal.

Fino Traço, Belo Horizonte.

TERRA. 2015. Link para consulta: https:// www.terra.com.br/noticias/brasil/ beneficiarios-do-bolsa-familia-tem-maiorqueda-de-natalidade,fc4c26eabe57c410 VgnVCM4000009bcceboaRCRD.html

VIANNA, Adriana de Resende Barreto. 2013. "Introdução: fazendo e desfazendo inquietudes no mundo dos direitos". In: VIANNA, Adriana (org.), O fazer e o desfazer dos direitos: experiências etnográficas sobre política, administração e moralidades. Rio de Janeiro, E-papers, pp. 36-67.
VIANNA, Adriana. 2015. "Tempos, dores e corpos: considerações sobre a 'espera' entre familiares de vítimas de violência policial no Rio de Janeiro". In: BIRMAN, Patrícia et al. (Eds.). Dispositivos urbanos e trama dos viventes: ordens e resistências. Rio de Janeiro, FGV editora.

Vianna, Adriana; Lowenkron, Laura. 2017. O duplo fazer do gênero e do Estado: interconexões, materialidades e linguagens. Cadernos Pagu, n. 51: e175101. DOI. https://doi.org/10.1590/18094449201700510001

ZELIZER, Viviana. 2009. Dualidades perigosas. Mana - Estudos de Antropologia Social, v. 15, n. 1: 237-256. DOI: https://doi. org/10.1590/S0104-93132009000100009.

ZELIZER, Viviana. 2011. A negociação da intimidade. Coleção Sociologia. Petrópolis, Vozes.

WEBER, Florence. 2009. Trabalho fora do trabalho: uma etnografia das percepções. Tradução de Roberta Ceva. Rio de Janeiro, Garamond.

Recebido em 21 de abril de 2020 . Aceito em 16 de dezembro de 2020 . 